\title{
Superior Visible-light Assisted Water Splitting Performance by Fe incorporated $\mathrm{ZnO}$ Photoanodes
}

\author{
Humaira Rashid Khan, a,b,c \\ a Materials Laboratory, Department of Chemistry, Mirpur University of Science and \\ technology (MUST), Mirpur-10250 (AJK), Pakistan. \\ bSchool of Materials, The University of Manchester, Oxford Road, Manchester M13 9PL, UK, \\ ${ }^{\mathrm{c}}$ Environment and Sustainability Institute (ESI), University of Exeter Penryn, Cornwall, TR10 \\ 9FE, UK.
}

Muhammad Aamir, ${ }^{a}$

${ }^{a}$ Materials Laboratory, Department of Chemistry, Mirpur University of Science and Technology (MUST), Mirpur-10250 (AJK), Pakistan.

\section{Bilal Akram}

Department of Chemistry, Tsinghua University, Bijing China

Asif Ali Tahir, ${ }^{\mathrm{c}}$

${ }^{\mathrm{c}}$ Environment and Sustainability Institute (ESI), University of Exeter Penryn, Cornwall, TR10 9FE, UK.

Mohammad Azad Malik, ;*

${ }^{\mathrm{b}}$ School of Materials, The University of Manchester, Oxford Road, Manchester M13 9PL, UK

Muhammad Aziz Choudhary ${ }^{\mathrm{a}}$

a Materials Laboratory, Department of Chemistry, Mirpur University of Science and Technology (MUST), Mirpur-10250 (AJK), Pakistan.

\section{Javeed Akhtar ${ }^{a *}$}

a Materials Laboratory, Department of Chemistry, Mirpur University of Science and Technology (MUST), Mirpur-10250 (AJK), Pakistan.

Email: javeed.chem@must.edu.pk, Azad.malik@manchester.ac.uk 


\begin{abstract}
Transition metal ion incorporation has been emerged as an effective stratagem to enhance the performance of metal oxide photoanodes. In the present work, we design and fabricate the plain $\mathrm{ZnO}$ and $(2,5,10$ and 15\%) Fe incorporated $\mathrm{ZnO}$ photoanode by aerosol assisted chemical vapor deposition (AACVD) method. The $15 \% \mathrm{Fe}$ incorporated $\mathrm{ZnO}$ photoanode displayed excellent photocurrent density of 4.6 $\mathrm{mA} / \mathrm{cm}^{2}$ at $0.7 \mathrm{~V} \mathrm{Ag} / \mathrm{AgCl}$ with photo conversion efficiency of $2.4 \%$, which is 159 times higher than pure $\mathrm{ZnO}$ photoanode $\left(0.028 \mathrm{~mA} / \mathrm{cm}^{2}\right)$. The obtained results are remarkably superior to the previous results. Furthermore, the Fe incorporated photoelectrodes have also shown good stability. The excellent photoelectrochemical performance of $\mathrm{Fe}$ incorporated $\mathrm{ZnO}$ showed red shift in band edge with relative decrease in the band gap energy compared to pure $\mathrm{ZnO}$. The demonstration of this simple method for the deposition of Fe incorporated $\mathrm{ZnO}$ to fabricate highly efficient photoanode for the PEC water splitting can easily be applied to other similar systems.
\end{abstract}

Keywords: PEC, Fe incorporated $\mathrm{ZnO}$, photoanodes, AACVD, Wurtzite

\title{
Introduction
}

Metal chalcogenide semiconductors have been extensively focused by the research community in the past few decades due to their wide spread energy applications like sensors, battery, photovoltaics and photoelectrochemical (PEC) devices. ${ }^{1-6}$ A variety of n-type semiconductors such as $\mathrm{TiO}_{2}, \mathrm{WO}_{3}, \alpha-\mathrm{Fe}_{2} \mathrm{O}_{3}, \mathrm{BiVO}_{4}$, $\mathrm{ZnO}$ and (oxy)nitrides have been developed as photoanodes for photoelectrochemical water splitting. ${ }^{7}$ Among all the mentioned photoanodes, $\mathrm{ZnO}$ is used as an attractive candidate for photoelectrochemical water splitting. ${ }^{8} \mathrm{ZnO}$ is thermodynamically stable 
at room temperature in hexagonal wurtzite phase, in which each cation $\left(\mathrm{Zn}^{2+}\right)$ is surrounded by four anions $\left(\mathrm{O}^{2-}\right)$ at the corners of tetrahedron. Generally, $\mathrm{ZnO}$ is considered as a wide band gap semiconductor with an energy gap of $3.44 \mathrm{eV}$ at low temperature and $3.37 \mathrm{eV}$ at room temperature. Large exciton binding energy, high optical transmittance, high electron mobility, high thermal conductivity, non-toxicity, high chemical and thermal stability, and low cost make $\mathrm{ZnO}$ as a potential candidate for applications in liquid crystal displays, transparent conducting electrodes in solar cells, light emitting diodes, thin film transistors, gas sensing and photoelectrochemical water splitting. ${ }^{9-11}$ The specific positions of valence and conduction band edges are also favourable for water redox reaction. However, wide band gap of $\mathrm{ZnO}(3.37 \mathrm{eV})$ enables it to utilize only ultraviolet (UV) light for water splitting.

During the past years, several attempts have been made to activate $\mathrm{ZnO}$ in the visible region of the spectrum including dye sensitization, ${ }^{12}$ addition of sacrificial agent/carbonate salt, composite semiconductor, ${ }^{13}$ and incorporation of metal ions. ${ }^{14,15}$ However, in order to improve the properties of $\mathrm{ZnO}$ for the mentioned applications, incorporation of metal ions is considered as an effective method. ${ }^{16}$ Developing highly effective yet essentially robust photoelectrodes capable of harnessing the full solar spectrum is the core task in this field. Moreover, in the interest of fully utilizing intermittent solar energy, integrating PEC cells with other electrochemical devices such as batteries and capacitors to simultaneously harvest, store, and release solar energy is appealing as well. Overall, efforts inspired from a broad range of scientific areas will be highly desirable to allow future breakthroughs in the promotion of PEC technology. ${ }^{17}$ 
Incorporation with selective metal ions can help to improve the structural, electrical and optical properties of $\mathrm{ZnO}$ and shifts its photoresponse to the visible region of the spectrum ${ }^{18}$ Mostly $3 \mathrm{~d}$ transition metals like Ti, V, Cr, Mn, Fe, Co, Ni and $\mathrm{Cu}$ are used for the incorporation in $\mathrm{ZnO}$ lattice. ${ }^{19,20} \mathrm{Fe}$ is considered as an effective dopant due to its chemical stability and existence in two possible oxidation states, $\mathrm{Fe}^{+2}$ and $\mathrm{Fe}^{+3}$. Additionally, the ionic radius of $\mathrm{Fe}^{+2}$ and $\mathrm{Fe}^{+3}(0.78$ and 0.64 $\AA)$ are close to the ionic radius of $\mathrm{Zn}^{+2}(0.74 \AA)$. Therefore, it can be easily incorporated into $\mathrm{Zn}$ lattice sites either substitutionally or interstitially without distorting the crystal structure of $\mathrm{ZnO}$ with greater contribution of charge carriers for the improvement of properties of $\mathrm{ZnO} .{ }^{21}$ Various physical and chemical methods have been applied for the fabrication of Fe incorporated $\mathrm{ZnO}$ thin films including radio frequency (RF) sputtering, direct current (DC) sputtering, ${ }^{22,23}$ sol-gel, ${ }^{24}$ chemical vapor deposition, ${ }^{25}$ spray pyrolysis, ${ }^{26}$ hydrothermal process,${ }^{27}$ electrodeposition ${ }^{28}$ and dip coating technique. ${ }^{29}$ Chemical vapour deposition (CVD) method has gained much importance in past few years for the fabrication of thin films of oxide materials and metal-chalcogenide. A modified form of CVD i.e. aerosol assisted chemical vapours deposition (AACVD) is used for the efficient deposition of thin films on different substrates. This is versatile method because of its fast coating rate, wider choice and availability of the precursors, controlled films morphology and easy way to deposit thin films in short time period. ${ }^{30}$

Herein, we report the fabrication of pure $\mathrm{ZnO}$ and $\mathrm{Fe}$ incorporated $\mathrm{ZnO}$ photoanodes via aerosol assisted chemical vapour deposition method for high performance photoelectrochemical water splitting. The $\mathrm{ZnO}$ thin films incorporated with different $\mathrm{Fe}$ concentrations $(2 \%, 5 \%, 10 \%$ and $15 \%)$ have shown improved light 
absorption with expanding absorption range to visible range. The as-deposited thin films were characterized by various techniques. The Fe- $\mathrm{ZnO}$ photoanodes has shown enhanced photocurrent density (159 times higher than of plain $\mathrm{ZnO}$ films) and good stability.

\section{Experimental Section:}

\section{Materials}

Zinc acetate dihydrate, (99.9\%, Sigma Co.), iron (III) nitrate nonahydrate, (99.9\% Sigma Co.) and methanol (99.9 \% Sigma Co.) were used without further purification.

\section{Characterizations}

The crystal structures of $\mathrm{ZnO}$ and $\mathrm{Fe}$ incorporated $\mathrm{ZnO}$ thin films (photoelectrodes) were studied by D2 ADVANCE XRD (Bruker, Germany) using Cu.K $\alpha$ radiation $(\lambda=1.54178 \AA$ ) $)$, in a $2 \Theta$ range from $15^{\circ}$ to $80^{\circ}$. FESEM TESCAN MIRA3XMU Scanning Electron Microscope (SEM) along with EDX (JEOL, USA) was used for the study of structural morphology and SHIMADZU UV 1800 Spectrophotometer was used for the measurement of the reflectance of the thin films.

\section{Photoelectrochemical Measurements}

The photoelectrochemical measurements were carried out in a three-electrode system. The Fe incorporated $\mathrm{ZnO}$ was used as working electrode having a surface area of about $1.6 \mathrm{~cm}^{2}$, Pt wire was used as counter electrode and $\mathrm{Ag} / \mathrm{AgCl}$ was used as reference electrode respectively. The electrolyte used for photoelectrochemical water splitting was $1 \mathrm{M} \mathrm{Na}_{2} \mathrm{SO}_{4}$ solution. The as-deposited photoanodes were illuminated through the electrolyte side and the illumination source was an AM 1.5 class A solar simulator (Solar Light 16S-300 solar simulator). The photocurrent was measured 
under the applied potential by an Auto lab PGSTAT12 potentiostat. The cyclic voltammetry and photo stability were also measured to check the PEC performance.

\section{Fabrication of Iron Incorporated ZnO Thin Films}

The thin films of pure and $\mathrm{Fe}$ incorporated $\mathrm{ZnO}$ were deposited on glass substrate by using home-built aerosol assisted chemical vapour deposition method (AACVD). The experimental setup detailed description of AACVD is reported earlier. ${ }^{31-34}$ Briefly, the precursor solution was prepared by mixing varying concentrations $(2 \%, 5 \%, 10 \%$ and $15 \%$ ) of iron (III) nitrate nonahydrate with zinc acetate dihydrate in $20 \mathrm{~mL}$ methanol solution. The resulting solution was transferred to two necked round bottom flask and placed in water bath above an ultrasonic humidifier where the aerosols were generated. The aerosols were transferred to the reaction chamber by using argon as a carried gas with the reaction temperature set at $400{ }^{\circ} \mathrm{C}$ for 2 hours. In order to check the photoelectrochemical water splitting performance, same procedure of thin films deposition was repeated using FTO substrate.

\section{Electrode Preparation}

Photoelectrochemical (PEC) studies were carried out using fluorine doped Tin oxide (FTO) conducting glass substrates. FTO substrates were cleaned by sonication, in $30 \mathrm{~mL}$ acetone and then in $25 \mathrm{~mL}$ of deionized water for 20 min each. The deposition of pure $\mathrm{ZnO}$ and iron (III) incorporated $\mathrm{ZnO}$ was performed on FTO substrate as discussed above via AACVD method. The as-obtained thin films on FTO substrates with iron (III) incorporated (2-15\%) were used as working electrodes for Photoelectrochemical (PEC) measurements. The electrical contact of these films during photoelectrochemical measurements was made by connecting the uncoated area of the thin film surface with an alligator clip connector. 


\section{Results and Discussion}

In the present work, the deposition of pure $\mathrm{ZnO}$ and $\mathrm{Fe}$ incorporated $\mathrm{ZnO}$ photoanodes were carried out using AACVD at $400{ }^{\circ} \mathrm{C}$. As far as we know, this is the first report on the designing of such photoanodes using above mentioned deposition technique for efficient photoelectrochemical water splitting. Pure $\mathrm{ZnO}$ films have shown compact film with typical morphology as shown in figure 1(a). As observed, all the crystallites have exhibited mixed morphologies (spherical and elongated) and average size of about $1.50 \pm 3 \mu \mathrm{m}$. When $\mathrm{ZnO}$ was incorporated with various concentrations of $\mathrm{Fe}(2 \%, 5 \%, 10 \%$ and $15 \%)$, the morphologies of the as-deposited films were changed as displayed to figure $1(b-e)$.

$2 \% \mathrm{Fe}$ incorporated $\mathrm{ZnO}$ films have shown the globular structures fused to form cluster and the average size of these clusters were increased compared to pure $\mathrm{ZnO}$ (figure 1(b)). Further increase in $\mathrm{Fe}$ incorporation in $\mathrm{ZnO}$ of $5 \%$ has changed the film morphology of variable shapes and sizes. The formation of these structures suggests that higher Fe concentration may lead to development of more defined shaped $\mathrm{ZnO}$ crystallites as displayed in figure $1(\mathrm{~d})$. Interestingly, $10 \% \mathrm{Fe}$ incorporation in $\mathrm{ZnO}$ has shown the formation of well-defined hexagonal shaped crystallites of variable sizes stacked over one another as shown in figure 1(e). Similar hexagonal structures were also reported by Meng et.al. ${ }^{35}$ for Fe doped $\mathrm{ZnO}$ nanoparticles synthesized via parallel flow precipitation method. We further increase the concentration of $\mathrm{Fe}$ into $\mathrm{ZnO}$ matrix to $15 \%$. In this extreme concentration of Fe, nanorods of $\mathrm{Fe}-\mathrm{ZnO}$ were appeared as presented in figure 1(e). Such a high quality nanorods, which were well dispersed 
onto the surface of the thin film have shown high surface area, which provides a basis for enhanced photoelectrochemical water splitting.
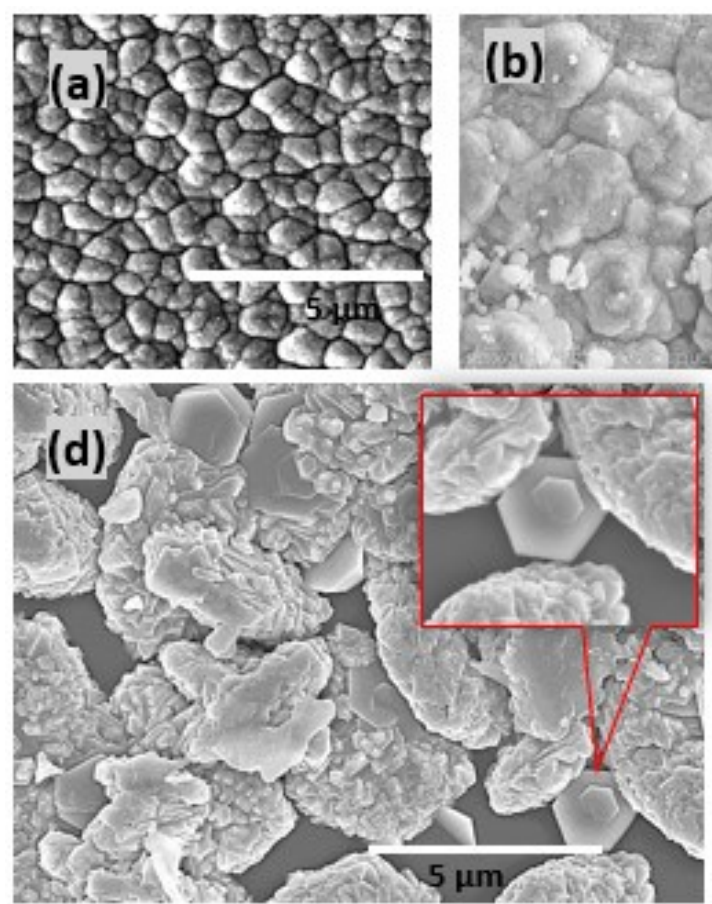
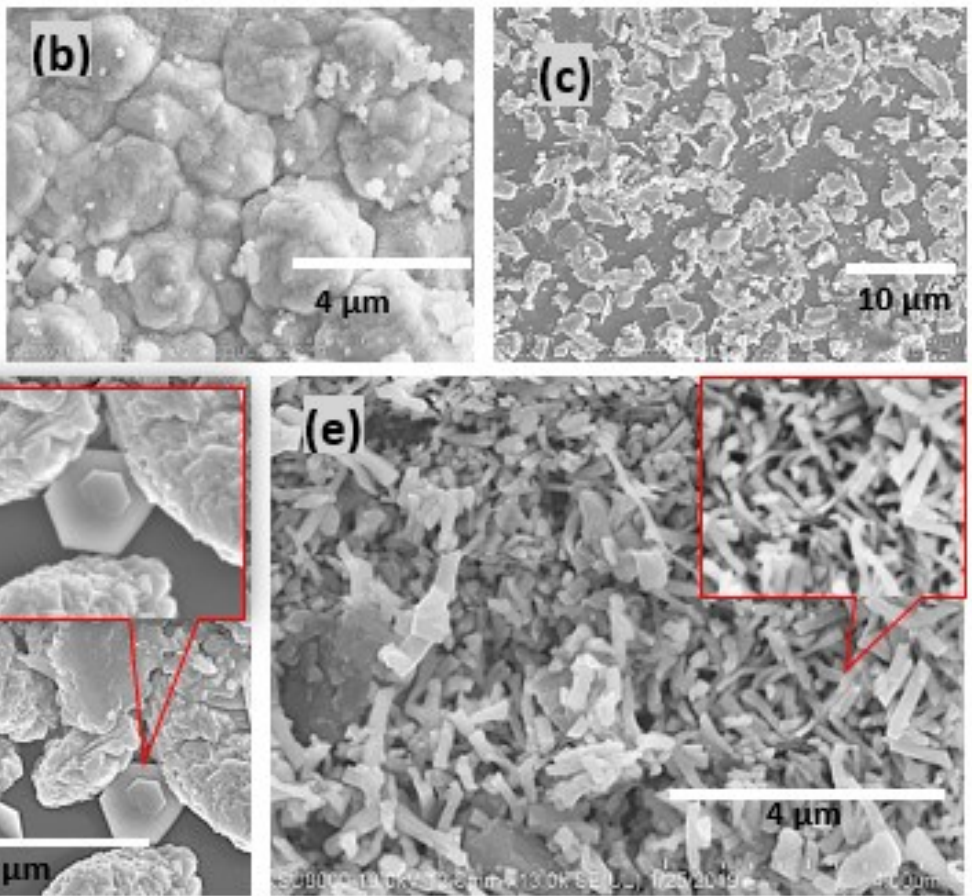

Figure 1. FESEM images of as-deposited photoanodes of (a) plain $\mathrm{ZnO}$ and (b) $2 \%$ (c) $5 \%$, (d) $10 \%$, (e) $15 \%$ Fe incorporated $\mathrm{ZnO}$ deposited by using AACVD method at $400{ }^{\circ} \mathrm{C}$.

The structural development of the as-deposited thin films of $\mathrm{ZnO}$ and $\mathrm{Fe}-\mathrm{ZnO}$ has been further analyzed by the powder X-ray diffraction (pXRD) measurements. Figure 2(a) shows the $\mathrm{pXRD}$ patterns of pure $\mathrm{ZnO}$ and $\mathrm{Fe}$ incorporated $\mathrm{ZnO}$ thin films with different concentrations of Fe. The diffraction peaks of the pure $\mathrm{ZnO}$ thin film were index to the wurtzite phase of $\mathrm{ZnO}$ confirmed by the presence of (100), (002), (101), (102), (110), (103), (112) and (201) planes (JCPDS: 01-089-0510). The absence of impurity peak indicates that as-obtained films are highly phase pure. Furthermore, the pure $\mathrm{ZnO}$ film has high diffraction peak intensity showing the high degree of crystallinity in pure $\mathrm{ZnO}$ films. The diffraction peaks of planes (100), (002) and (101) 
were recorded to be the most intense peaks. However, the peak intensity of these planes have shown progressive degradation with increasing Fe incorporation in $\mathrm{ZnO}$ lattice. This peak degradation was showing the effect of Fe incorporation on the growth kinetics of $\mathrm{ZnO}$ films. The change in growth kinetics of $\mathrm{Fe}$ incorporated $\mathrm{ZnO}$ films mainly associated with the incorporation of new nucleation centres, their saturations, and change in energy at the time of collision and the physical and chemical interactions. ${ }^{36}$ The diffraction peak intensity was decreased gradually with increasing Fe concertation in $\mathrm{Fe}-\mathrm{ZnO}$ films suggesting that the $\mathrm{ZnO}$ crystallinity was decreased due to $\mathrm{Fe}$ incorporation in $\mathrm{ZnO}$. The optical properties of pure $\mathrm{ZnO}$ and $\mathrm{Fe}$ incorporated $\mathrm{ZnO}$ films were studied by $\mathrm{UV}$-visible diffuse reflectance spectroscopy (UV/DRS) as shown in Figure 2(b). As presented in figure 2(b), the absorption band of $\mathrm{ZnO}$ was shifted to visible region with iron incorporation into the $\mathrm{ZnO}$ matrix. In pure $\mathrm{ZnO}$, the band edge absorption was appeared at $380 \mathrm{~nm}$, which was expanded to higher wavelength with increasing concentration of Fe suggesting a decrease in the band gap of thin films. Furthermore, the absorption peak intensity of $\mathrm{ZnO}$ films was increased with the decrease in reflectance from $74 \%$ for $\mathrm{ZnO}$ with $2 \% \mathrm{Fe}$ and $57 \%$ for $15 \% \mathrm{Fe}$ in $\mathrm{ZnO}$, respectively. The red shift in band edge absorption is probably due to the d-d transition of Fe (III) or the charge transfer transition between interacting Fe ions ${ }^{37}$ and due to sp-d exchange interaction between the band electrons and the localized " $d$ " electrons of the $\mathrm{Fe}^{+3}$ ion at cationic site. ${ }^{38}$ The change in colour of the as-deposited photoanodes with increasing concentration of $\mathrm{Fe}$ incorporation in $\mathrm{ZnO}$ thin films can be observed in the figure 2(c). 
(a)

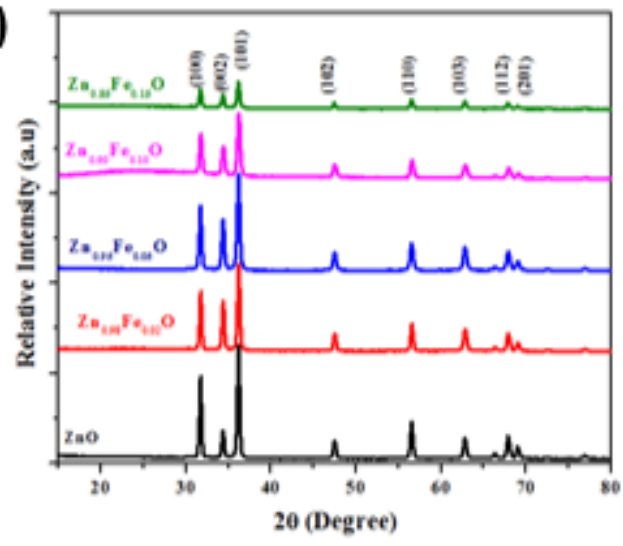

(c)

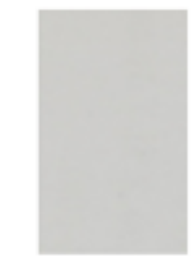

$\mathrm{ZnO}$

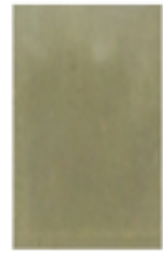

$\mathrm{Zn}_{0.95} \mathrm{Fe}_{0.02} \mathrm{O}$
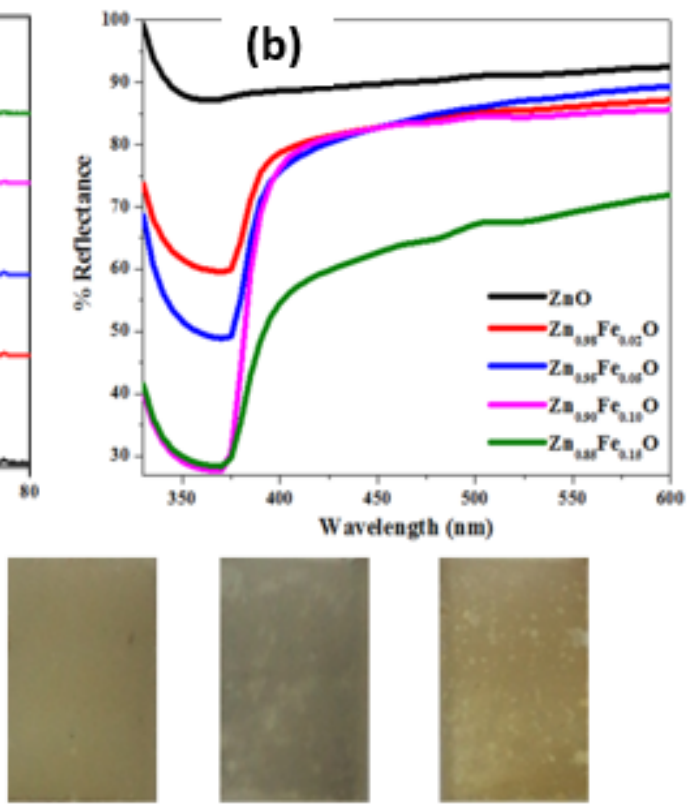

$\mathrm{Zn}_{0.95} \mathrm{Fe}_{0.05} \mathrm{O}$

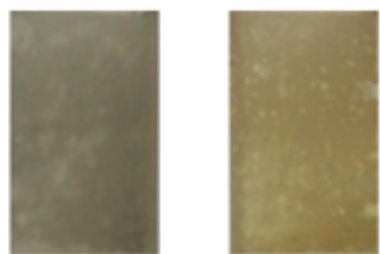

$\mathrm{Zn}_{0.90} \mathrm{Fe}_{0.10} \mathrm{O} \quad \mathrm{Zn}_{0.95} \mathrm{Fe}_{0.18} \mathrm{O}$

Increasing Fe concentration in ZnO

(d)

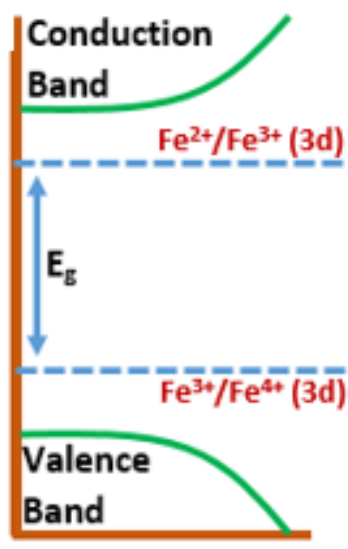

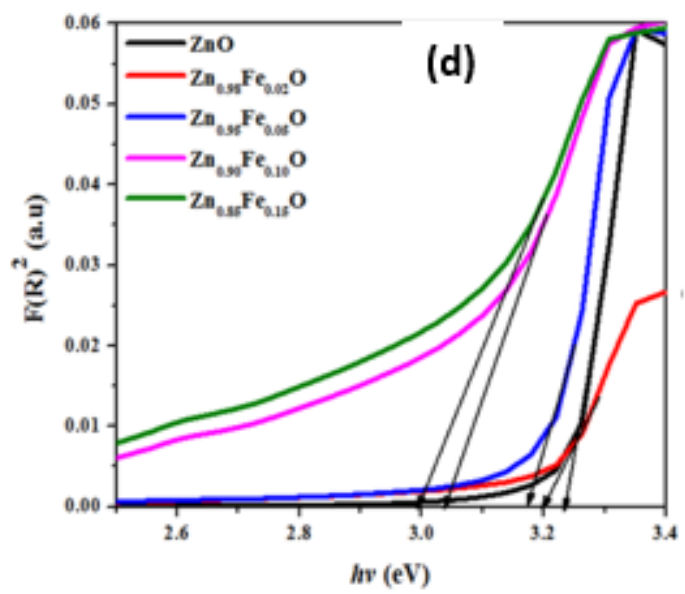

Figure 2. (a) pXRD pattern, (b) UV-Visible diffused reflectance spectra, (c) the color change of the thin films with increasing concentration of $\mathrm{Fe}$ in $\mathrm{ZnO}$, (d) band gap energy level diagram and (e) plot of $(\mathrm{F}(\mathrm{R}) \mathrm{hv})^{2}$ versus photon energy $(\mathrm{eV})$ using Kubelka-Munk method of pure $\mathrm{ZnO}$ and Fe incorporated $\mathrm{ZnO}\left(\mathrm{Zn}_{1-\mathrm{x}} \mathrm{Fe}_{\mathrm{x}} \mathrm{O}\right)$ photoanodes $(\mathrm{x}=0.02,0.05 .0 .10$ and 0.15$)$.

The incorporation of $\mathrm{Fe}$ in $\mathrm{ZnO}$ substituted the $\mathrm{Zn}$ ions and introduced the new energy levels into the bands. Two types of energy levels can be introduced by the Fe ions in $\mathrm{ZnO}$. One above the valence band due to the $3 \mathrm{~d}$ orbital of $\mathrm{Fe}^{3+}$ and other is 
below the conduction band due to the $3 \mathrm{~d}$ orbital of $\mathrm{Fe}^{2+} \cdot{ }^{38}$ As a result, the level of conduction band is decreased and level of valence band is upgraded leading to decrease in band gap as shown in figure 2(d).

The Kubelka-Munk function is applied to evaluate the bandgap energy of asdeposited photoanodes (figure 2e). The optical band gap of pure $\mathrm{ZnO}$ was found to be $3.25 \mathrm{eV}$, which become $3.2 \mathrm{eV}, 3.18 \mathrm{eV}, 3.08 \mathrm{eV}$ and $2.98 \mathrm{eV}$ for $2 \%, 5 \%, 10 \%$ and $15 \%$ ) for $\mathrm{Fe}$ incorporated $\mathrm{ZnO}$ photoanodes, respectively. These values were according to the reported literature. ${ }^{39}$ The reduction in band gap is mainly due to the presence of new energy levels below the conduction band and above the valence band of $\mathrm{ZnO}$, reduces the energy required for transitions from valence band to conduction band. ${ }^{40,41}$

\section{PEC Performance}

PEC water splitting performance was analysed to determine the photoactivities of pure $\mathrm{ZnO}$ and $\mathrm{Fe}$ incorporated $\mathrm{ZnO}$ photoanodes fabricated by AACVD method. In this context, the electrochemically active surface area (ECSA) for pure $\mathrm{ZnO}$ and $\mathrm{Zn}_{1-\mathrm{x}} \mathrm{Fe}_{\mathrm{x}} \mathrm{O}(\mathrm{x}=2 \%, 5 \%, 10 \%$ and $15 \%)$ photoanodes were evaluated from the electrochemical capacitance of the electrode-electrolyte interface (EDLC). Electrochemical capacitance was measured by using cyclic voltammograms potentiostatically cycled in the range of -0.6 to $0.6 \mathrm{~V}$ versus $\mathrm{Ag} / \mathrm{AgCl}$ as shown in the figure 4 (a-d). 

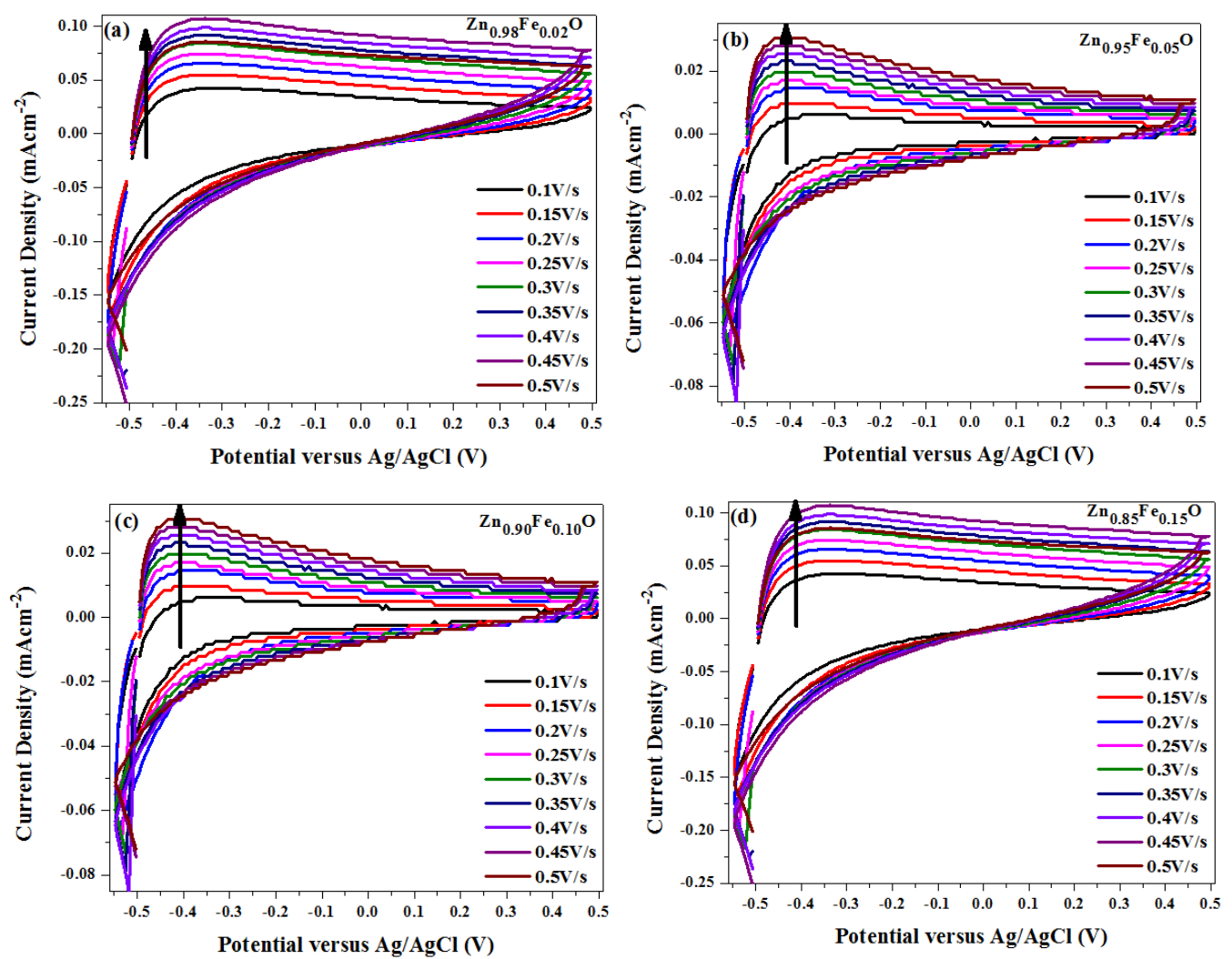

Figure 4. (a-d) Cycle voltammetry curves for Fe incorporated $\mathrm{ZnO}$ photoelectrodes. $(0.02,0.05,0.10$ and 0.15$)$

The electrochemical double-layer capacitance (cdl) is directly dependent on the ECSA and the scan rate. It can be obtained by calculating the slope of the linear relationship shown in figure 5 . The cdl of all the as-deposited photoanodes were found to be $25,148,188$ and $195 \mathrm{mF} / \mathrm{cm}^{2}$. As observed, the electrochemical effective surface area of $\mathrm{ZnO}$ increased rapidly with increasing Fe incorporation in $\mathrm{ZnO}$. The maximum cdl value of $15 \% \mathrm{Fe}-\mathrm{ZnO}$ suggests more active sites available for PEC activity. 


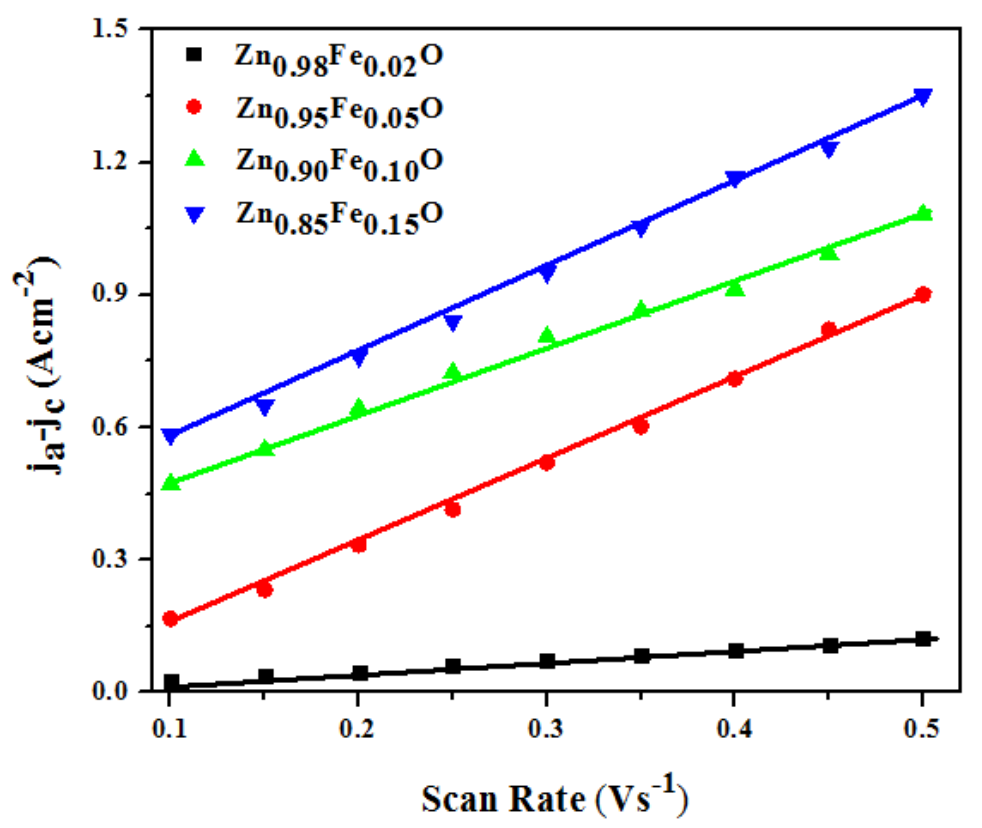

Figure 5. Double layered Capacitance calculated from the cyclic voltammetry curves at different scan rates.

Figure 6(a) showed the photocurrents generated from pure $\mathrm{ZnO}$ and Fe incorporated $\mathrm{ZnO}$ photoanodes between potentials of $(-0.5$ to $0.5 \mathrm{~V} \mathrm{Ag} / \mathrm{AgCl})$. The dark current for all the photoanodes was negligible. Whereas, under light illumination, pure $\mathrm{ZnO}$ photoanode produces a photocurrent density of $0.27 \mathrm{~mA} / \mathrm{cm}^{2}$. As observed, Fe incorporated $\mathrm{ZnO}$ photoanodes showed significant improvement in the photocurrent density compared to $\mathrm{ZnO}$ photoanodes. For Fe incorporated $\mathrm{ZnO}$ photoanodes, the photocurrent intensity at potential of $0.5 \mathrm{~V} \mathrm{Ag} / \mathrm{AgCl}$ was increased significantly from 1.98, 2.46, 3.38 and $4.57 \mathrm{~mA} / \mathrm{cm}^{2}$ for $\mathrm{Zn}_{0.98} \mathrm{Fe}_{0.02} \mathrm{O}(2 \% \mathrm{Fe}), \mathrm{Zn}_{0.95} \mathrm{Fe}_{0.05} \mathrm{O}(5 \% \mathrm{Fe})$, $\mathrm{Zn}_{0.90} \mathrm{Fe}_{0.10} \mathrm{O}(10 \% \mathrm{Fe})$, and $\mathrm{Zn}_{0.85} \mathrm{Fe}_{0.15} \mathrm{O}(15 \% \mathrm{Fe})$ respectively. The photocurrent density of $15 \%$ Fe incorporated $\mathrm{ZnO}$ photoanode was 159 times superior to pure $\mathrm{ZnO}$. The superior current density for $15 \% \mathrm{Fe}$ incorporated $\mathrm{ZnO}$ was due to the band gap extended to visible range and the morphology of the as-deposited photoanodes compared to $\mathrm{ZnO}$ photoanodes with low Fe concentrations. 
Salem et al. ${ }^{42}$ have reported the photocurrent density of $0.024 \mathrm{~mA} / \mathrm{cm}^{2}$ for $0.5 \% \mathrm{Fe}$ doped $\mathrm{ZnO}$ photoanode. On the other hand, Yang et al. $^{43}$ have developed $\mathrm{ZnO} / \mathrm{ZnFe}_{2} \mathrm{O}_{4}$ hetero-nanostructured photoanodes showed a photocurrent density of $1.41 \mathrm{~mA} / \mathrm{cm}^{2}$. Dom et al. ${ }^{44}$ have also fabricated the Fe doped $\mathrm{ZnO}$ photoanodes by spray pyrolysis technique and have reported the photocurrent density of $0.22 \mathrm{~mA} / \mathrm{cm}^{2}$. However, in present study, we have achieved the photocurrent density of $4.6 \mathrm{~mA} / \mathrm{cm}^{2}$, which highest from the previous reports. The superior photocurrent density for $15 \%$ Fe incorporated $\mathrm{ZnO}$ usually related with the crystal defects and domain confinements which could lead to the formation of charge trapping centres resulting in the improvement of charge separation at the interface of $\mathrm{ZnO}$ and the electrolyte used and hence enhanced the photoelectrochemical water splitting. ${ }^{45}$ The linear sweep voltammetry curves (LSV) for the as-deposited photoanodes under chopped light illumination are shown in figure 6(b). As observed, all the as-deposited photoanodes have shown reproducible photoresponse. Under light radiation, the photocurrent has shown spike and then it became steady rapidly. After the interruption of light, the photocurrent density was dropped quickly to almost zero. Moreover, the photocurrent depends upon the applied potential, since it increases as the applied potential is scanned towards more positive values. Among all the photo-anodes, $\mathrm{Zn}_{0.85} \mathrm{Fe}_{0.15} \mathrm{O}$ showed maximum photocurrent density due to slow recombination of electron and holes. ${ }^{46}$ The increased photocurrent density of the Fe incorporated $\mathrm{ZnO}$ suggests that the separation and transferring of photogenerated charges are highest for $15 \% \mathrm{Fe}$ incorporated $\mathrm{ZnO}$. 

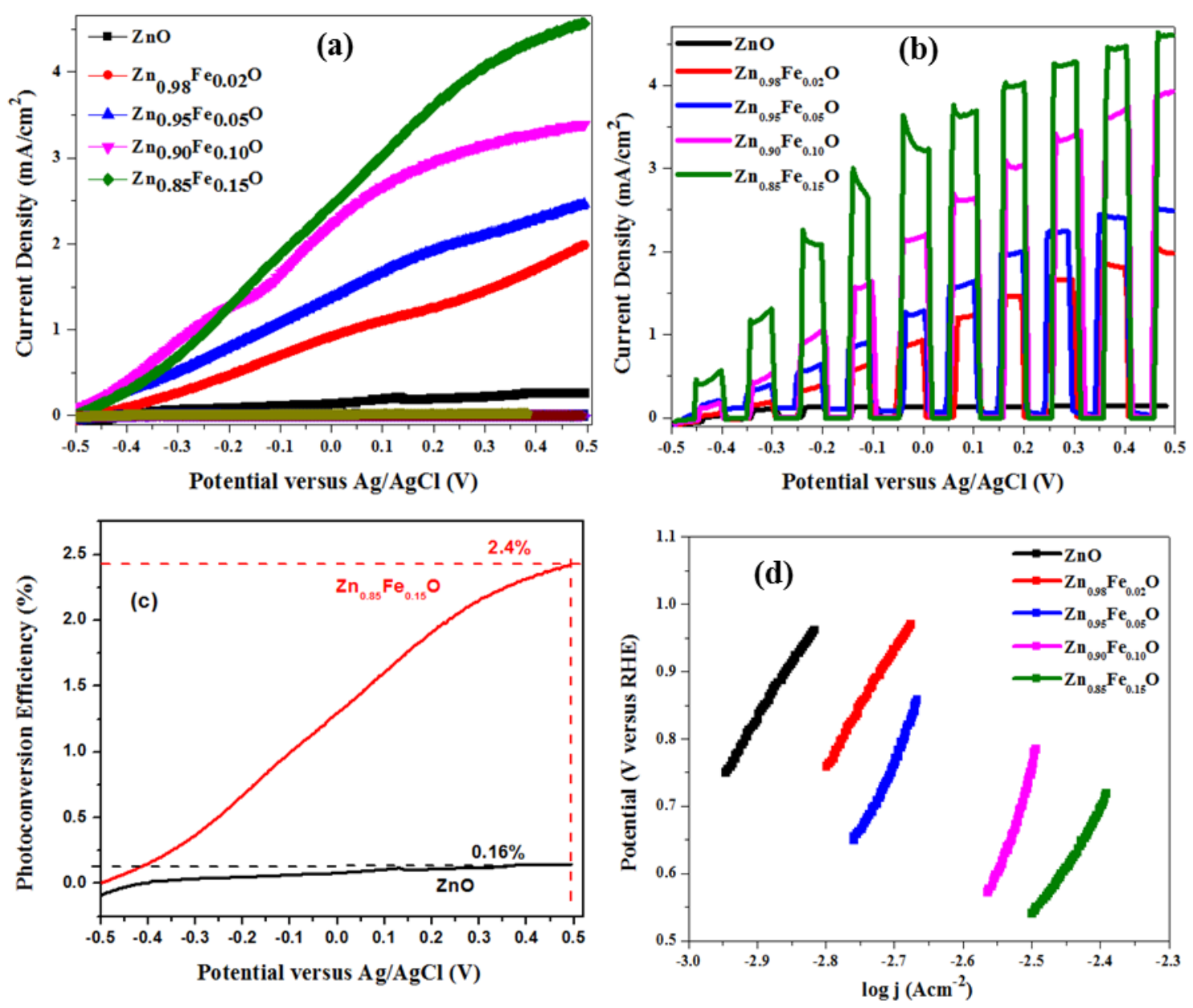

Figure 6. (a) Linear Sweep Voltammetry (LSV) curves (b) Chopped under light and dark conditions for pure and iron incorporated $\mathrm{ZnO}$, (c) photo-conversion efficiency of the pure $\mathrm{ZnO}$ and $15 \% \mathrm{Fe}$ incorporated $\mathrm{ZnO}$ photoanode at an applied potential and (d) Tafel plot of as-deposited pristine $\mathrm{ZnO}$ and $\mathrm{Zn}_{1-\mathrm{x}} \mathrm{Fe}_{\mathrm{x}} \mathrm{O}(\mathrm{x}=0.02,0.05,0.10$ and 0.15) photoelectrodes in $0.1 \mathrm{M} \mathrm{Na}_{2} \mathrm{SO}_{4}$ solution.

The photo-conversion efficiency of the $15 \%$ Fe incorporated $\mathrm{ZnO}$ photoanodes was calculated by using equation $1 .{ }^{43}$

$$
\eta=\frac{I(1.23-V)}{J}
$$

Where, $\eta$ is the photo-conversion efficiency, I is the measured photocurrent $\left(\mathrm{mA} / \mathrm{cm}^{2}\right)$, $\mathrm{V}$ is the applied voltage $(\mathrm{V})$ and $\mathrm{J}$ is the incident light radiation $\left(\mathrm{mM} / \mathrm{cm}^{2}\right)$. As shown in figure $6(\mathrm{c})$, the photo-conversion efficiency was found to be $0.15 \%$ at the applied 
potential of $0.5 \mathrm{~V}$ vs $\mathrm{Ag} / \mathrm{AgCl}$. Whereas, $15 \% \mathrm{Fe}$ incorporated $\mathrm{ZnO}$ photoanode has displayed an optimum photo-conversion efficiency of around $2.4 \%$ at an applied bias of $0.5 \mathrm{~V}$ vs $\mathrm{Ag} / \mathrm{AgCl}$. Compared to various previous reports of $\mathrm{Fe}$ doped $\mathrm{ZnO}$ photoanodes, our results were remarkably high. ${ }^{42-44}$ Obviously, the superior results in our study are highly competitive compared to related materials.

To gain more critical insights into the photoelectrochemical reaction kinetics, Tafel plots were determined as shown in figure 6(d). The value of Tafel slope for pure $\mathrm{ZnO}$ photoanode was found to be $304 \mathrm{mV} / \mathrm{dec}$. Whereas, the Tafel slope values for $2 \%, 5 \%$, $10 \%$ and $15 \%$ Fe incorporated $\mathrm{ZnO}$ photoanode was found to be $226,165,157$ and $146 \mathrm{mV} / \mathrm{dec}$. respectively. The lowest Tafel slope value for $15 \% \mathrm{Fe}$ incorporated $\mathrm{ZnO}$ $\left(\mathrm{Zn}_{0.85} \mathrm{Fe}_{0.15} \mathrm{O}\right)$ photoanodes could be justified by the increased activity of iron due to electronic interaction between iron and zinc and high catalytic activity resulting from the effect of back bonding of iron. ${ }^{47,48}$

Stability is an important factor to validate the application of photoanodes. Therefore, the photocurrent density-time curve at $0.5 \mathrm{~V}$ versus $\mathrm{Ag} / \mathrm{AgCl}$ for about 10 seconds per cycle as shown in figure 7. Under discontinuous illumination for 900 seconds, the decline in photocurrent density was negligible. This confirms the quick transference of electrons and stability of the photoanodes. ${ }^{49}$ Among different chronoamperometric measurements of as-deposited thin films, $\mathrm{Zn}_{0.85} \mathrm{Fe}_{0.15} \mathrm{O}$ showed maximum stability in light. This enhancement of photo-response of $\mathrm{Zn}_{0.85} \mathrm{Fe}_{0.15} \mathrm{O}$ photoanode is possibly because of the higher absorbance and better separation of photogenerated electron-hole pairs. ${ }^{50}$ 


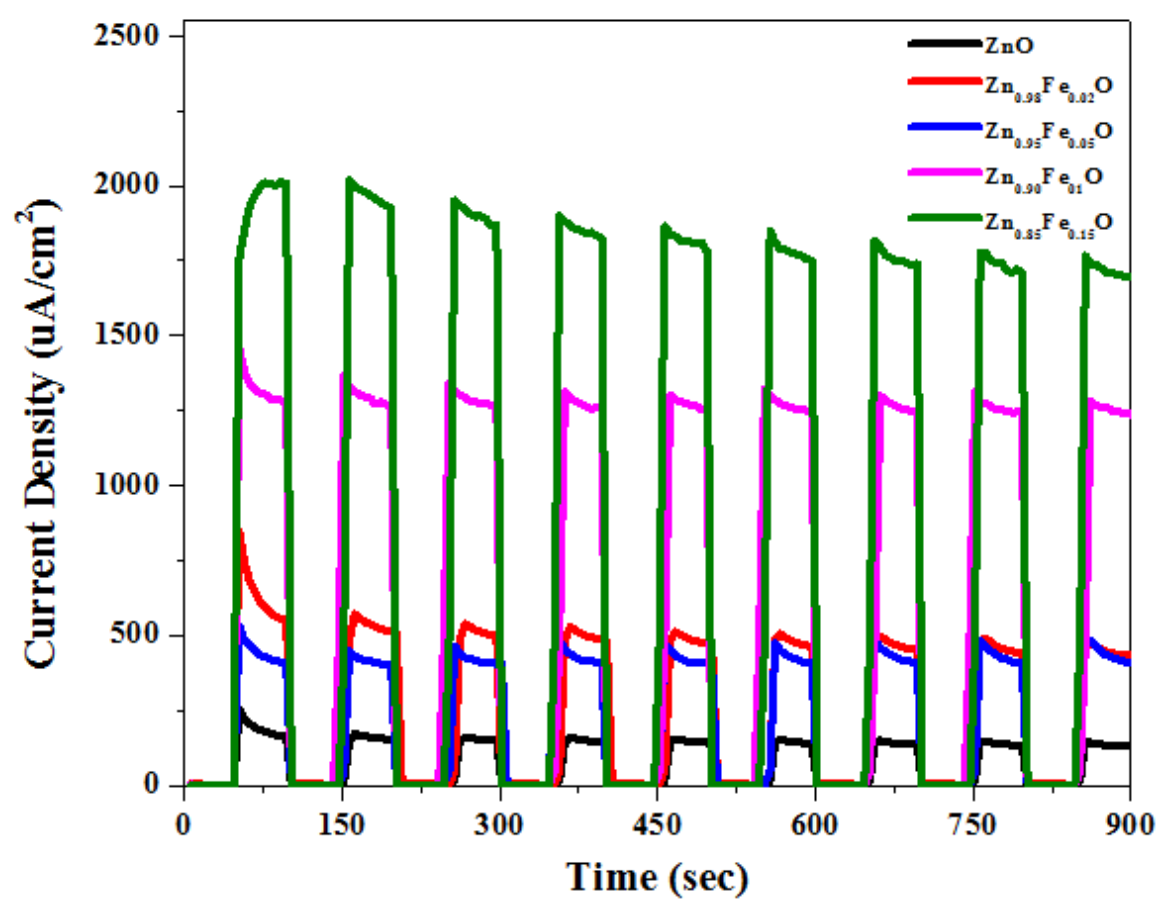

Figure 7. Chronoamperometric measurements of as-deposited Pristine $\mathrm{ZnO}$ and $\mathrm{Zn}_{1-}$ ${ }_{x} \mathrm{Fe}_{\mathrm{x}} \mathrm{O}(\mathrm{x}=0.02,0.05,0.10$ and 0.15$)$ thin films.

\section{Conclusion}

A simple and facile approach was adopted to prepare Fe incorporated $\mathrm{ZnO}$ photoanodes by using AACVD technique. The as-prepared photoanodes were characterized by powdered X-Ray diffraction (pXRD), field emission scanning electron microscopy (FESEM), UV-Visible reflectance spectroscopy. The Fe incorporation in $\mathrm{ZnO}$ has altered the band gap and extended it to visible range. The asdeposited photoanodes ( $\mathrm{Fe}$ incorporated $\mathrm{ZnO}$ ) have shown super photocurrent density with good stability.

\section{Acknowledgements:}

JA thanks HEC, Pakistan for financial grant \#8227 under NRUP-2018/19 scheme. 


\section{References}

(1) Khan, M. D.; Aamir, M.; Sohail, M.; Sher, M.; Akhtar, J.; Malik, M. A.; Revaprasadu, N. Solar Energy 2018, 169, 526.

(2) Khan, M. D.; Aamir, M.; Sohail, M.; Sher, M.; Baig, N.; Akhtar, J.; Malik, M. A.; Revaprasadu, N. Dalton Trans. 2018, 47, 5465.

(3) Khan, M. D.; Aamir, M.; Murtaza, G.; Malik, M. A.; Revaprasadu, N. Dalton Trans. 2018, 47, 10025.

(4) Adhikari, T.; Pathak, D.; Wagner, T.; Jambor, R.; Jabeen, U.; Aamir, M.; Nunzi, J.-M. Optical Mater. 2017, 73, 70.

(5) Jabeen, U.; Adhikari, T.; Shah, S. M.; Pathak, D.; Kumar, V.; Nunzi, J.-M.; Aamir, M.; Mushtaq, A. Chinese J. Phys. 2019, 58, 348.

(6) Khan, M. D.; Aamir, M.; Sohail, M.; Bhoyate, S.; Hyatt, M.; Gupta, R. K.; Sher, M.; Revaprasadu, N. Dalton Trans. 2019, 48, 3714.

(7) Bhatt, M. D.; Lee, J. S. J. Mater. Chem. A 2015, 3, 10632.

(8) Khan, H. R.; Akram, B.; Aamir, M.; Malik, M. A.; Tahir, A. A.; Choudhary, M. A.; Akhtar, J. Appl. Surface Sci. 2019, 490, 302.

(9) Oh, B.-Y.; Jeong, M.-C.; Moon, T.-H.; Lee, W.; Myoung, J.-M.; Hwang, J.-Y.; Seo, D.-S. J. Appl. Phys. 2006, 99, 124505. 
(10) Bakin, A.; El-Shaer, A.; Mofor, A. C.; Al-Suleiman, M.; Schlenker, E.; Waag, A. Phys. Stat. Solid. c 2007, 4, 158.

(11) Aamir, M.; Adhikari, T.; Sher, M.; Revaprasadu, N.; Khalid, W.; Akhtar, J.; Nunzi, J.-M. New J. Chem. 2018, 42, 14104.

(12) Bakin, A.; Behrends, A.; Waag, A.; Lugauer, H.-J.; Laubsch, A.; Streubel, K. Proceedings of the IEEE 2010, 98, 1281.

(13) Chen, H. M.; Chen, C. K.; Chang, Y. C.; Tsai, C. W.; Liu, R. S.; Hu, S. F.; Chang, W. S.; Chen, K. H. Angew. Chem. Int. Ed. 2010, 49, 5966.

(14) Maeda, K.; Takata, T.; Hara, M.; Saito, N.; Inoue, Y.; Kobayashi, H.; Domen, K. J. Am. Chem. Soc. 2005, 127, 8286.

(15) Yang, X.; Wolcott, A.; Wang, G.; Sobo, A.; Fitzmorris, R. C.; Qian, F.; Zhang, J. Z.; Li, Y. Nano Lett. 2009, 9, 2331.

(16) Khan, H. R.; Aamir, M.; Malik, M. A.; Tahir, A. A.; Akram, B.; Murtaza, G.; Choudhary, M. A.; Akhtar, J. Mater. Sci. Semicond. Process. 2019, 101, 223.

(17) Chiu, Y.-H.; Lai, T.-H.; Kuo, M.-Y.; Hsieh, P.-Y.; Hsu, Y.-J. APL Mater. 2019, 7, 080901.

(18) Akpan, U.; Hameed, B. Appl. Catal. A: General 2010, 375, 1.

(19) Seo, S.; Litao, Y.; Kim, H. Molecul. Crys. Liquid Crys. 2014, 602, 64.

(20) Saha, S. K.; Rahman, M. A.; Sarkar, M.; Shahjahan, M.; Khan, M. J. Semicond. 2015, 36, 033004.

(21) Han, C.; Duan, L.; Zhao, X.; Hu, Z.; Niu, Y.; Geng, W. J. Alloys Compd. 2019, 770, 854. 
(22) Hassan, M. M.; Khan, W.; Naqvi, A.; Mishra, P.; Islam, S. J. Mater. Sci. 2014, 49, 6248.

(23) Gao, F.; Liu, X. Y.; Zheng, L. Y.; Li, M. X.; Bai, Y. M.; Xie, J. J. Crys. Growth 2013, 371, 126.

(24) Srivastava, A.; Kumar, N.; Khare, S. Opto-Electron. Rev. 2014, 22, 68.

(25) Xu, W.; Ye, Z.; Zeng, Y.; Zhu, L.; Zhao, B.; Jiang, L.; Lu, J.; He, H.; Zhang, S. Appl. Phys. Lett. 2009, 94, 173506.

(26) Lmai, F.; Moubah, R.; El Amiri, A.; Abid, Y.; Soumahoro, I.; Hassanain, N.; Colis, S.; Schmerber, G.; Dinia, A.; Lassri, H. Optical Mater. 2016, 57, 28.

(27) Wu, X.; Wei, Z.; Zhang, L.; Wang, X.; Yang, H.; Jiang, J. J. Nanomater. 2014, 2014, 4.

(28) Awawdeh, M.; Al-Heuseen, K.; Odeh, I. 2014.

(29) Srinivasulu, T.; Saritha, K.; Reddy, K. R.

(30) Malik, S. N.; Malik, A. Q.; Mehmood, R. F.; Murtaza, G.; Alghamdi, Y. G.; Malik, M. A. New J. Chem. 2015, 39, 4047.

(31) Akhtar, J.; Malik, M. A.; O'Brien, P.; Helliwell, M. J. Mater. Chem. 2010, 20, 6116.

(32) Akhtar, J.; Malik, M. A.; O'Brien, P.; Wijayantha, K.; Dharmadasa, R.; Hardman, S. J.; Graham, D. M.; Spencer, B. F.; Stubbs, S. K.; Flavell, W. R. J. Mater. Chem. 2010, 20, 2336.

(33) Aamir, M.; Khan, M. D.; Sher, M.; Revaprasadu, N.; Malik, M. A.; Akhtar, J. New J. Chem. 2018, 42, 17181. 
(34) Aamir, M.; Sher, M.; Khan, M. D.; Malik, M. A.; Akhtar, J.; Revaprasadu, N. Mater. Lett. 2017, 190, 244.

(35) Meng, Q.; Lu, Q.; Wang, L.; Wang, J. In IOP Conference Series: Mater. Sci. Engineer.; IOP Publishing: 2018; Vol. 292, p 012065.

(36) Paraguay D, F.; Morales, J.; Estrada L, W.; Andrade, E.; Miki-Yoshida, M. Thin Solid Films 2000, 366, 16.

(37) Navío, J. A.; Colón, G.; Macías, M.; Real, C.; Litter, M. I. Appl. Catal. A: General 1999, 177, 111.

(38) Kim, K. J.; Park, Y. R. J. Appl. Phys. 2004, 96, 4150.

(39) Cheng, W.; Ma, X. In J. Phys.: Conference Series; IOP Publishing: 2009; Vol. 152, p 012039.

(40) Pal, B.; Sharon, M. Mater. Chem. Phys. 2002, 76, 82.

(41) Lavand, A. B.; Malghe, Y. S. J. King Saud Uni. Sci. 2018, 30, 65.

(42) Salem, M.; Akir, S.; Ghrib, T.; Daoudi, K.; Gaidi, M. J. Alloys Compd. 2016, 685, 107.

(43) Yang, T.; Xue, J.; Tan, H.; Xie, A.; Li, S.; Yan, W.; Shen, Y. J. Mater. Chem. A 2018, 6, 1210.

(44) Dom, R.; Baby, L. R.; Kim, H. G.; Borse, P. H. Int. J. Hydrogen Energy $\mathbf{2 0 1 7}, 42,5758$.

(45) Lin, Y. G.; Hsu, Y. K.; Chen, Y. C.; Lee, B. W.; Hwang, J. S.; Chen, L. C.; Chen, K. H. ChemSusChem 2014, 7, 2748.

(46) Sánchez-Tovar, R.; Fernández-Domene, R. M.; Montañés, M.; SanzMarco, A.; Garcia-Antón, J. RSC Adv. 2016, 6, 30425. 
(47) Xie, J.; Zhang, J.; Li, S.; Grote, F.; Zhang, X.; Zhang, H.; Wang, R.; Lei, Y.; Pan, B.; Xie, Y. J. Am. Chem. Soc. 2013, 135, 17881.

(48) Van Drunen, J.; Pilapil, B. K.; Makonnen, Y.; Beauchemin, D.; Gates, B. D.; Jerkiewicz, G. ACS Appl. Mater. Interfaces 2014, 6, 12046.

(49) Chen, C. K.; Shen, Y. P.; Chen, H. M.; Chen, C. J.; Chan, T. S.; Lee, J. F.; Liu, R. S. Eur. J. Inorg. Chem. 2014, 2014, 773.

(50) Zhang, Y.; Lu, J.; Hoffmann, M. R.; Wang, Q.; Cong, Y.; Wang, Q.; Jin, H. RSC Adv. 2015, 5, 48983. 